\title{
SUPERIOR OPHTHALMIC VEIN PUNCTURE
}

\section{An alternative approach to treat complex cavernous sinus fistulae}

\author{
Eduardo Wajnberg', Gabriela Z. Spilberg², Emerson L. Gasparetto³
}

Complex cavernous sinus fistulae (CCF) are a technical challenge to neuro-vascular specialists. Their clinical symptoms are usually a triad of chemosis, ptosis and exophthalmia ${ }^{1,2}$. Among the most serious symptoms are visual loss, and consequences of brain hemorrhage. The most commonly performed endovascular treatment consists in embolization through a venous approach by the inferior petrosal sinus and occlusion of the cavernous sinus with coils. Not always a conventional route is feasible, imposing alternative routes. We describe two cases of CCF treated with technical success using the superior ophthalmic vein (SOV) as a route to reach the cavernous sinus.

\section{CASES}

Case 1

A 73 year-old male presented with acute-onset right periocular pain, diplopia, ocular injection, progressive proptosis, and periocular swelling after an episode of trauma. His past medical history was unremarkable.

The CT scan of the brain demonstrated enlargement of the right SOV posterior to the eye globe. A cerebral angiography demonstrated a direct carotid cavernous dural sinus fistula. The right internal carotid artery supplied the fistula, but also the posterior circulation, due to the presence of a persistent trigeminal artery. The fistula drained only to the anterior compartment of the cavernous sinus, through the superior ophthalmic vein. There was no suitable alternative access to the fistula: the inferior petrosal sinus was occluded and the angular and facial veins were tortuous, such that accessing the fistula through these routes would be difficult (Fig 1). Direct balloon embolization was discarded because of the risk of occluding the persistent trigeminal artery, which was calibrous. An endovascular attempt to recanalize the inferior petrous sinus was unsuccessful. Conventional surgery with direct occlusion of the cavernous sinus was attempted, but also not successful, as the patient remained symptomatic and control angiograms done in the post-

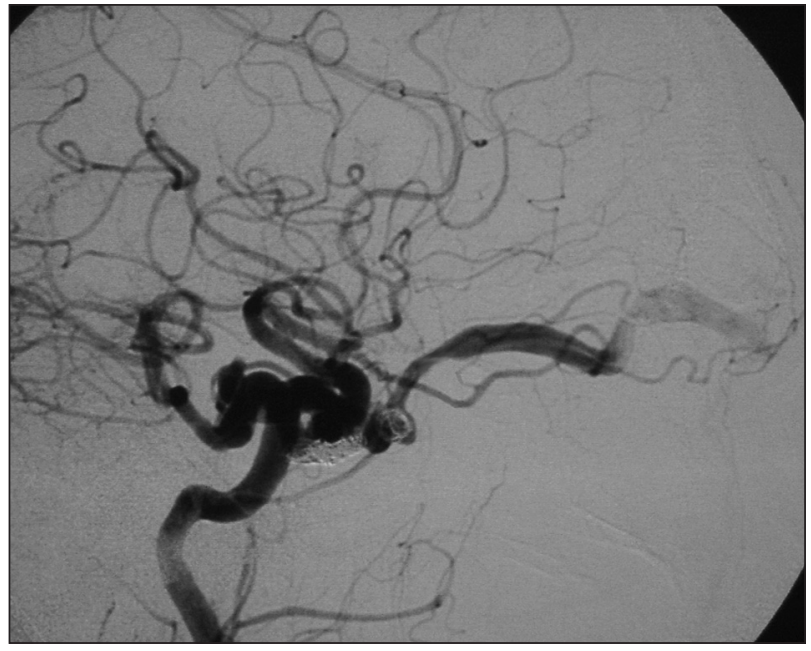

Fig 1. Patient 1. Left carotid angiography despicting a carotid-cavernous direct fistula, with exclusive venous drainge by a dilated SOV and a proeminant persistent trigeminal artery.

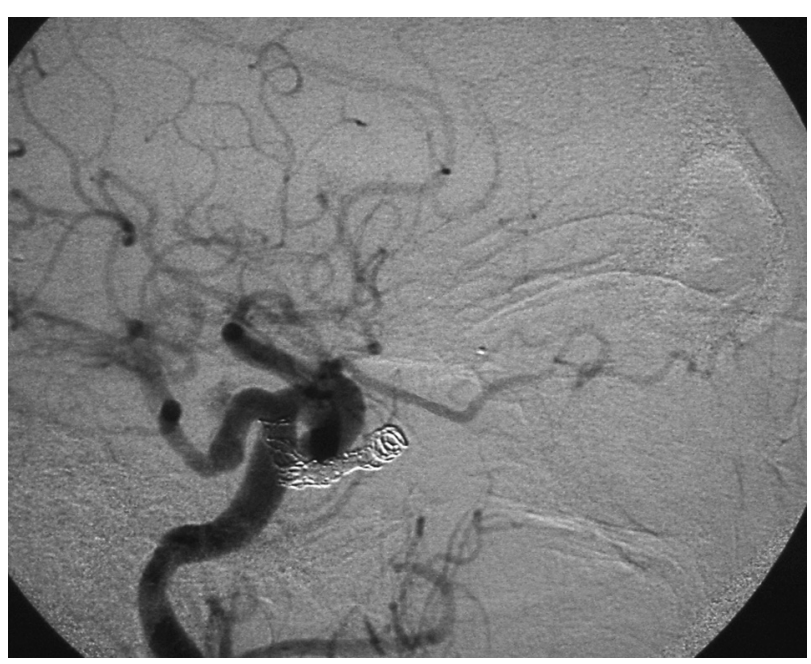

Fig 2. Patient 1. Post-therapeutic angiogram demonstrating total occlusion of the fistula, with added coils inside the cavernous sinus.

\section{PUNÇÃO DA VEIA OFTÁLMICA SUPERIOR: UMA VIA ALTERNATIVA PARA TRATAMENTO DE FÍSTULAS CARÓTIDO-CAVERNOSAS COMPLEXAS}

Departamento de Radiologia da Universidade Federal do Rio de Janeiro (UFRJ), Rio de Janeiro RJ, Brasil: 'Médico Neuroradiologista Intervencionista do Departamento de Radiologia da UFRJ; ${ }^{2}$ Residente do Segundo Ano do Departamento de Radiologia da UFRJ; ${ }^{3}$ Professor Adjunto do Departamento de Radiologia da UFRJ.

Received 6 November 2008, received in final form 25 January 2009. Accepted 29 April 2009.

Dr. Eduardo Wajnberg - Rua Lopes Quintas 100 / 602 - 22460-010 Rio de Janeiro RJ - Brasil. E-mail: eduardowj@gmail.com 


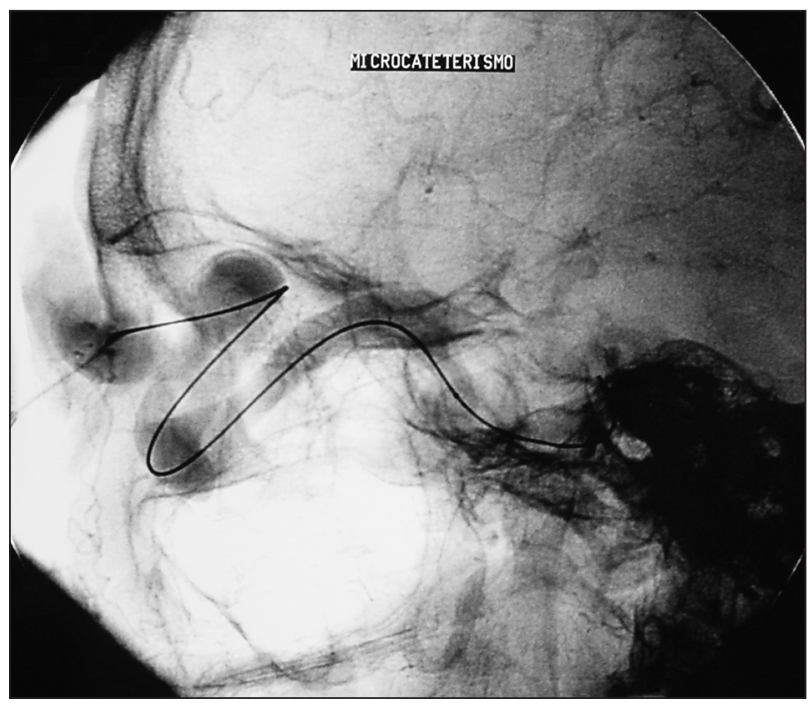

Fig 3. Patient 2. Lateral vertebral angiography showing microcatheter navigation throw a large and tortuous SOV.

operative period showed partial occlusion of the cavernous sinus and persistence of the fistula. At this point it was decided to access the cavernous sinus via direct puncture of the SOV.

The patient was placed under general anesthesia. After the arterial anatomy of the lesion was studied through a complete 4 vessels angiography, a 5 French catheter was placed in the carotid artery for observation of the shunt, angiographic control and road mapping. After surgical dissection of the right SOV, the puncture was done with 20G-Teflon intravenous type-catheter, and a microcatheter (Tracker Excel 14- Boston Scientific, Freemont, CA) was placed directly through it. The correct position of the microcatheter was confirmed with both transvenous and transarterial angiography. Embolization was performed using Guglielmi detachable platinum coils (Boston Scientific/Target, Fremont, CA) and Hidrogel 14 coils (MicroVention, Inc., Aliso Viejo, CA). With progressive packing of the fistulous pouch, transarterial angiography was repeated sequentially until no evidence of fistulous drainage was visible. The patient recovered well, remaining with a residual diplopia.

\section{Case 2}

A 65 year-old woman presented with a 15 year-history of proptosis, low visual acuity and a pulsatile supraorbital mass. There was no history of trauma. Her past medical history was remarkable for Chagas disease, with cardiomyopathy.

The CT scan of the brain demonstrated a giant SOV and exuberant venous collateral circulation in the supraorbital region and forehead. A cerebral angiography was done, which demonstrated a direct carotid cavernous dural sinus fistula. Both internal carotids were occluded at origin, and recanalization of the distal segments through anastomotic branches of the external carotid arteries was observed. The fistula was fed mainly by the posterior circulation. The direct puncture of the SOV was chosen as the via to access the cavernous sinus.

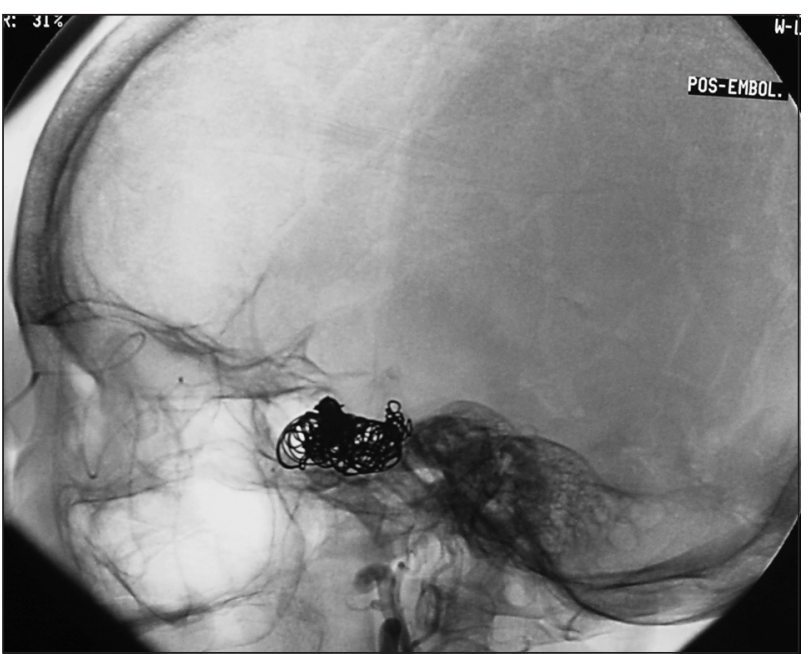

Fig 4. Patient 2. Post-embolization aspect, with a dense coil cast inside the cavernous sinus.

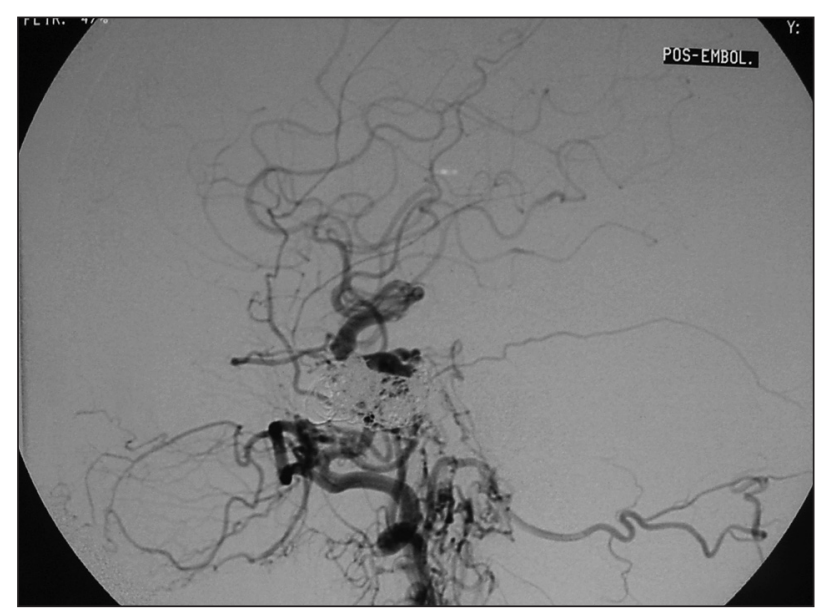

Fig 5. Patient 2. Post-embolization, left vertebral angiogram, showing internal carotid oclusion and recanalization by external carotid branches, and complete angiographic cure of the fistula.

After the arterial anatomy of the lesion was studied through a complete 4 vessels angiography, a 5 French catheter was placed in the left vertebral artery for observation of the shunt and angiographic control. Road-map images of the venous phase were obtained through transarterial injections from the carotid artery catheter, to guide the venous puncture and microcatheter navigation. The puncture of a collateral enlarged supra-orbitary vein was done with 20G-Teflon intravenous type-catheter, and a microcatheter (Tracker Excel 14- Boston Scientific, Freemont, CA) was placed directly through it. There was no surgical exposure of the vein, as in Case 1. The puncture was done under direct road map visualization. The correct position of the microcatheter was confirmed with both transvenous and transarterial angiography. Embolization was achieved using DCS 18 (Cook, Bloomington, IN, USA). With progressive packing of the fistulous pouch, transarterial angiography was repeated sequen- 
tially until no evidence of fistulous drainage was visible. There was immediate closure of the fistula, with shrinkage of the supraorbital pulsatile mass (Figs 2,3,4,5). Six months after the procedure, the patient remained with mild proptosis.

\section{DISCUSSION}

Intracranial dural arteriovenous fistulae are acquired arteriovenous shunts located inside the dura-mater. They account for $10-15 \%$ of all intracranial arteriovenous lesions $^{3}$. Their arterial supply arises from meningeal branches of the internal or external carotid arteries, and rarely from cortical branches. The clinical presentation of dural fistulae is due to arterialization of the venous system. CCF usually presents with neuro-ophtalmologic symptoms secondary to ophthalmic veins arterialization ${ }^{4,5}$, such as chemosis (88\%), exoftalmos (70\%), III cranial nerve palsy $(35 \%)$, VI nerve palsy (64\%) and bruit (47\%) in a series presented by Klisch et al. ${ }^{6}$. Acute-onset fistulae or high flow fistulae may also be associated with periocular swelling. Patients with visual deterioration require early intervention to preserve their sight. Once visual loss is complete, even with treatment, optic nerve function is hardly recovered $^{7,8}$. When cortical drainage is present, there is a major risk factor to intra-parenchymal hemorrhage 3 . The clinical presentation of our patients was periocular pain, diplopia, ocular injection, proptosis, periocular swelling, low visual acuity and a pulsatile mass.

The CT scans in patients with dural vascular malformations are often normal. Sometimes enlargement of a dural sinus or a dilated draining vein can be identified. In carotid cavernous fistulae an enlarged cavernous sinus is seen in half of cases, and a dilated superior ophthalmic vein can be identified on most contrast-enhanced scans. On magnetic resonance studies, the finding of dilated cortical veins without an identifiable parenchymal nidus suggests the presence of a dural shunt. Routine $\mathrm{T} 1$ and T2, spin echo weighted MR images can demonstrate complications of dural fistula, such as infarction and hemorrhage. Conventional MRI is less successful at direct visualization of the exact fistula site, although dural engorgement can sometimes be seen on post-contrast studies. Enlarged superior ophthalmic vein are readily identifiable 9 . In our cases, the pre-treatment CT scan findings were enlargement of the SOV and collateral circulation.

Manual carotid-jugular or ocular compression was a classically proposed therapeutic method for $\mathrm{CCF}^{8,10}$, not frequently used today. It may precipitate vaso-vagal attack or even isquemic stroke. Hamby and Gardner in 1933 described the first successful intracranial ligation of the carotid artery for treatment of this disease ${ }^{11}$. Endovascular treatment of direct CCFs has evolved since the introduction of detachable balloons ${ }^{12}$ and is now the definitive treatment of high-flow traumatic lesions because of its safety and efficacy ${ }^{13}$. However, indirect CCFs are rarely, if ever, curable with balloon occlusion or particulate embolization, because the complex arterial supply from multiple ECA and/or cavernous ICA branches ${ }^{13}$.

Trans-arterial treatment may be performed ${ }^{2,14}$; particulate arterial embolization may result in angiographic immediate cure of the fistulae in up to $50 \%$ of cases, but delayed recanalization, or change in drainage pattern usually is observed. It may specially be effective when the patient is oligosymptomatic ${ }^{3}$ and the fistula is fed only by meningeal branches of the external carotid artery.

Arterial embolization with glue also can be performed ${ }^{3}$, but only in cases of simple fistulae with a single pedicle, or few dilated pedicles. Injection should be done only if distal catheterization allows good flow control, enabling glue to reach the venous side. In these cases, complete cure of the fistulae may be achieved.

Transvenous embolization has become the treatment of choice for such lesions ${ }^{15}$ after the introduction of this method by Uflacker et al. in $1986^{16}$. Generally, an approach may be performed trough the femoral vein and inferior petrosal sinus. When the inferior petrosal sinus is not opacified, an attempt to catheterize or recanalize it must be made ${ }^{17,18}$. It may be impossible because of thrombosis or anatomic variation, such as cases of plexiform inferior petrosal sinus or absence of connection with the jugular vein ${ }^{8}$. An alternative to these cases is catheterization of the facial and angular veins ${ }^{6,8}$. This may be technically very difficult owing to the tortuosity of the vein. In these cases, direct puncture of the SOV, percutaneously or after surgical exposure, may be a good alternative ${ }^{19,20}$.

The complications of this approach include risk of damage to the trochlea or other orbital structures, causing retro-ocular hemorrhage and infection. Other potential complications include injury of the supra-orbital nerve or elevator palpebrae muscle ${ }^{21}$. Goldberg et al. concluded that, if the SOV is not dilated, or if it is located deep in the orbit, then trasorbital venous approach may not be possible ${ }^{22}$. Miller et al. reported severe visual loss and neurovascular glaucoma complicating the SOV approach ${ }^{23}$. Devoto et al. described acute exophtalmus occurring during treatment of a carotid-cavernous fistula via the SOV ${ }^{24}$. Aihara et al. reported worsening of ocular symptoms occurring after occlusion of the cavernous sinus ${ }^{25}$. Fukami et al. described late central retin vein occlusion after transvenous embolization of a DAVF ${ }^{26}$.

In our cases, we chose the venous approach due to the safety and efficacy of this type of treatment. In Patient 1 there was no route except for the SOV. The angular vein was too tortuous and the inferior petrosal sinus was occluded. An attempt was made to recanalize it, but it was worthless. Even surgical direct embolization failed, and the only choice left was surgical exposure and di- 
rect puncture of the SOV. In Patient 2 both internal carotids were occluded at origin, and there was an exuberant SOV and collateral circulation, making it a good and easy approach.

There weren't any technical difficulties or complications in our cases with the direct transvenous approach of the SOV. It can be reached either with surgical exposure or catheterization trough a collateral vein. When other routes are not available, the superior ophtalmic vein puncture is a feasible approach and carries a low risk of complications.

\section{REFERENCES}

1. Kim MS HD, Kwon OK, Oh CW, Han MH. Clinical characteristics of dural arteriovenous fistula. J Clin Neurosci 2002;9:147-155.

2. Michels KS NJ, Falardeau J, Roberts WG, Petersen B, Nesbit GM, Barnwell SL. Transvenous embolization of a dural carotid-cavernous sinus fistula via the inferior ophthalmic vein. Ophthalmic Plastic Reconstructive Surgery 2007;23:480-482.

3. Kiyosue H HY, Okahara M, Tanoue S, et al. Treatment of intracranial dural arteriovenous fistulas: current strategies based on location and hemodynamics, and alternative techniques of transcatheter embolization. Radiographics 2004;24:1637-1653.

4. Lasjaunias P CM, ter Brugge K, Tolia A, Hurth M, Bernstein M. Neurological manifestations of intracranial dural arteriovenous malformations. J Neurosurgery 1986;64:724-730.

5. Stiebel-Kalish H SA, Nimii Y, Kalish Y, et al. Cavernous sinus dural arteriovenous malformations: patterns of venous drainage are related to clinical signs and symptoms. Ophthalmology 2002;109:1685-1691.

6. Klisch JMDH, Juergen H, Spestzger U, Hetzel A, Wolfgang S, Schumach M. Transvenous treatment of carotid cavernous and dural arteriovenous fistulae: results for 31 patients and review of the literature. Neurosurgery 2003;53:836-857.

7. Albuquerque FC, McDougall CG. Reversal of blindness after transvenous embolization of a carotid-cavernous fistula: case report. Neurosurgery 2003;52:233-237.

8. Yu SC CH, Wong GK, Chan CM, Cheung JY, Poon WS. Transvenous embolization of dural carotid-cavernous fistulae with transfacial catheterization through the superior ophthalmic vein. Neurosurgery 2007;60:1032-1037.

9. Tsai MYF, Chen LK, Su CT, Lu TN, Wu CC, Kuo CJ. Utility of source images of three-dimensional time-of-flight magnetic resonance angiography in the diagnosis of indirect carotid-cavernous sinus fistulas. J Neuro-Ophthalmology 2004;24:285- 289.

10. Higashida RT HG, Halbach VV, Bentson JR, Goto K. Closure of carotid cavernous sinus fistulae by external compression of the carotid artery and jugular vein. Acta Radiol 1986; 369(Suppl):S580-S583.

11. Hamby WBGW. Treatment of pulsating exophtalmus: report of 2 cases. Arch Surg Chicago 1933;27:676-678.

12. Liang MW, Xiaofeng $Y$, Weiguo L, et al. . Bilateral traumatic ca- rotid cavernous fistula: the manifestations, transvascular embolization and prevention of the vascular complications after therapeutic embolization. J Craniofacial Surgery 2007;18: 74-77.

13. Koebbe CJ, Jungreis C, Levy E, Pless M. Alcohol embolization of carotid-cavernous indirect fistulae. Neurosurgery 2003;52: 1111-1116.

14. Satomi J, Satoh K, Matsubara S, Nakajima N, Nagahiro S. Angiographic changes in venous drainage of cavernous sinus dural arteriovenous fistulae after palliative transarterial embolization or observational manangement: a proposed stage classification. Neurosurgery 2005;56:494-502.

15. Hara T, Hamada JI, Kai Y, Ushio Y. Surgical transvenous embolization of a carotid-cavernous dural fistula with cortical drainage via a petrosal vein: two technical case reports. Neurosurgery 2002;50:1380-1384.

16. Uflacker R LS, Ribas GC, Piske RL. Carotid-cavernous fistulas: embolization through the superior ophthalmic vein approach. Radiology 1986;159:175-179.

17. Cheng CMC, Cheung YL. Transvenous embolisation of dural carotid-cavernous fistulas by multiple venous routes: a series of 27 cases. Acta Neurochirurgica 2003;145:17-29.

18. Benndorf G BA, Lehmann R, Lanksch W. Transvenous occlusion of dural cavernous sinus fistulas through the thrombosed inferior petrosal sinus: report of four cases and review of the literature. Surg Neurol 2000;54:42-54.

19. Miller PS. Cook detachable coil embolization of a symptomatic, isolated orbital arteriovenous fistula via a superior ophthalmic vein approach. Intervent Neuroradiol 2005;47:62-65.

20. Quiñones D DG, Gobin PY, Goldberg RA, Viñuela F. Embolization of dural cavernous fistulas via superior ophthalmic vein approach. AJNR Am J Neuroradiol 1997;18:921-928.

21. Oishi H AH, Sato K, Iizuka Y. Complications associated with transvenous embolisation of cavernous dural arteriovenous fistula. Acta Neurochir (Wien) 1999;141:1265-1271.

22. Goldberg RA GS, Duckwiler G, Vinuela F. Management of cavernous sinus-dural fistulas. Indications and techniques for primary embolization via the superior ophthalmic vein. Arch Ophthalmol 1996;114:707-714.

23. Miller NR ML, Debrun GM, Tamargo RJ, Nauta HJ. Treatment of carotid-cavernous sinus fistulas using a superior ophthalmic vein approach. J Neurosurg 1995;83:838-842.

24. Devoto MH EJ, Tomsick TA, Kulwin DR. Acute exophthalmos during treatment of a cavernous sinus-dural fistula through the superior ophthalmic vein. Arch Ophthalmol 1997;115:823-824.

25. Aihara N MM, Yamada K, Banno T, Watanabe K, Kamiya K, Takagi T. Deterioration of ocular motor dysfunction after transvenous embolization of dural arteriovenous fistula involving the cavernous sinus. Acta Neurochir (Wien). 1999;141:707-709.

26. Fukami T IT, Shiino A, Nakazawa T, Matsuda M, Handa J. Central retinal vein occlusion after embolization for spontaneous carotid cavernous sinus fistula. No Shinkei Geka 1996;24:749-753. 